Editorial

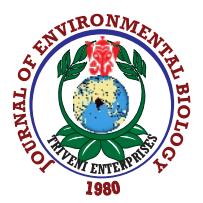

\title{
JEB's Journey - Research approach and expectations from researchers
}

The Journal of Environmental Biology is a well-known name in the research fraternity worldwide. It stands among the reputed International Journals published from India. The journal has grown and made tremendous progress during its journey of four decades. It has undergone rapid evolution in the last 40 years to become a competitive publication both at the national as well as international arena. It is a great challenge to run a journal independently, especially when it is not associated with any society. For the last four decades, an enormous amount of work has been done for the development of the journal, which is well reflected in every issue. The journal without fail has been disseminating scientific knowledge by publishing researches on varied areas of Environmental and Biological Sciences under the supervision of Dr. R.C. Dalela- Editor-in-chief.

This year we celebrated the $40^{\text {th }}$ anniversary of JEB. Now, the journal is well established and in a

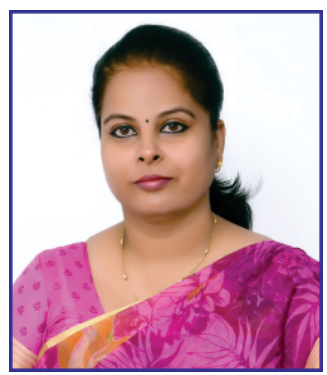
strong position. In his Editorial note-2019, Dr. Dalela had shared about the interesting journey of JEB. I hope our readers must have enjoyed reading it. As Editor of JEB, I feel privileged to be a part of this academic venture. Though during my doctorate days, I had hardly dreamt of taking editorship as a career. My transition from a researcher to a science editor has been exciting, satisfying and wonderful experience. No wonder, that acting as Editor of a journal is a vital and rewarding task. Apart from my regular chores as an editor, this year I was given some additional duties to plan out new strategy for the journal and give a fresh look to JEB. This responsibility was challenging, however, some ideas were presented to the Editor-in-chief by Members of Editorial Board, R\&D Professionals and after discussion with editorial staff, these were implemented.

In this editorial as an Editor, I would like to share my experiences and introduce changes made in the year 2020. While thinking of the journal's progress, the first thing that comes to my mind is submission of quality manuscripts and peer review system. Regarding submission, we constantly emphasize authors to visit our website and read "Guidelines for Authors" before submitting their research papers. Our Guidelines are very clear and comprehensive, therefore, new submissions, before initiating peer review process, are evaluated to check whether they fit the journal's scope and satisfy journals' criteria and standards. Till date, the journal has tried to maintain its standard by accepting quality manuscripts through a rapid and smooth review process. We have made the review system more critical by inviting experts to evaluate the technical merit of the research papers. The complete review process usually takes about two to three months, and much stress is being paid to speed up the review process. Here, I would like to state that the review process can only be expedited if the reviewers respond to requests immediately and are willing to perform peer review within a stipulated time frame. At times it is quite frustrating and disappointing that after several reminders we fail to receive the consent or review reports. This is one of the reasons for the delay in the review process. The editorial staff ensures that the review process is completed on time. Further, to enhance the quality and creditability, all the accepted papers are edited by editors, who are usually members of the Editorial Board or a subject expert. The critical and double-blind review system adopted by JEB is fair and unbiased and not only acts as a filter by eliminating lowquality papers but also provides constructive feedback to the authors to improve their manuscripts for future publication.

I believe that journal-benefits from strong Editorial Board as they act as good-will ambassadors for the journal. Frequently, we receive e-mails from fellow scientists, desiring to join the Editorial Board and volunteer to act as reviewers for the journal. This year we have made an attempt to globalize the editorial board by recruiting new members from diverse fields and expertise. Members of the Editorial Board will be nominated for a time period, and timely the Editorial Board would be renewed depending on their performance. Apart from providing advice and support to the editor, the Editorial Board members have been allotted additional responsibilities and functions. This year, we had extended invitations for writing editorials and review articles from the Editorial Board members and most of them have agreed. In the upcoming issues of 2020, readers would find Editorials as well as Review Articles of Editorial Board Members. 
Further, the members are entrusted to receive and recommend innovative research papers from their fellow Scientists/Researchers for publication in JEB. Personally, I am of the opinion that a column can be introduced in the journal under the heading "Research for Society Health" where an experienced active researcher should discuss his own expertise research with a motive of suggesting in what direction his research should be directed in the larger interest of society, supported by references to generate debate and motivation for new researchers. The journal is introducing a column in every issue under the caption "Current Research Report". For this section, scientists under single authorship can submit a two-page communication, which will be published with DOI number, Free of cost. The full-length paper of CRR will be published as per the Guidelines of CRR.

Despite high rejection rate, the journal receives submissions for regular as well as Special Issue. The rising popularity of JEB is also well reflected in the number of Special Issues from different countries published so far. This year we have published three Special Issues; two from overseas, China \& Korea and one from India. In the upcoming issues of 2020 also, we plan to release Special Issues on different themes. Plagiarism is another big issue we are cautious. At each stage of publication, right from submission to printing, all the papers are checked for plagiarism or any other unethical practices. The papers are out rightly rejected if they consist of plagiarized content. On the eve of $40^{\text {th }}$ year of successful publication, the management had instituted JEB International Award of Cash Prize USD $\mathbf{5 0 0}$ for the best paper published. From 2020, Young Researcher Award of Cash Prize USD 200, sponsored by Dalela Educational Foundation would be given to a young researcher for the best paper published in JEB. Thus, in a year, JEB will give two awards for Best Papers published. I have been associated with the Journal of Environmental Biology for about one decade. It is not only a privilege but a great honour for holding a responsible position in publication supervised by a renowned academician and researcher, Dr. Dalela, who has been a torchbearer to many researchers. Well, we all admire Dr. Dalela for his never-ending enthusiasm, loads of new innovative ideas and high spirit to reach newer heights, despite age and health issues.

JEB is incomplete without its in-house editorial staff. We have an array of young professionals who are not only dedicated, sincere, co-operative but self manageable and intelligent. Their contribution to JEB's success and popularity is noteworthy and commendable. We all work hard, hand in hand to make best efforts to publish good research. As an Editor of JEB, I have responsibilities to discharge, expectations to be fulfilled and maintain high standards of journal. Throughout my career as Technical Editor and Scientist-incharge of JEB, I have learnt a lot about publication, apart from my day-to-day work of handling manuscripts, interacting with authors/reviewers, taking decisions, policy making, and meeting publication deadlines. Each day I have learnt something new but still I feel that I have to learn a lot. The journal has paved its way and earned reputation. Not only as Editor-in-chief but also as an elderly scientist, Dr. Dalela has lot of expectations from me, and firmly believes "improvement is always possible". Therefore, it is not only my duty but also aspiration to make Journal of Environmental Biology as the Best Journal published from India.

Till date, authors, reviewers and members of editorial have been collegial towards the journal. Therefore, I would like each of you to open up the journal to new perspectives. As the ambassadors of the journal, I would like the members to help us to identify the topics and preferences of readers, within the scope of the journal. For future development and growth of the journal, I wish to get feedback about journal's performance. I wish that researchers from all round the world should submit their best innovative research in JEB. I remain at your service to improve the journal and welcome suggestions to maintain the highest standard for this journal.

Date: 30.12 .2019

\author{
Dr. Sumati Gaumat \\ Editor \& Scientist-in-charge, R\&D Division \\ Journal of Environmental Biology \\ 1/206, Vikas Nagar, Luclnow (India)
}

